\title{
R. Edward Carter, M.D. (Ed) 1928-2021
}

\author{
William Donovan $^{1}$
}

Published online: 14 April 2021

(c) The Author(s), under exclusive licence to International Spinal Cord Society 2021

Ed Carter was liked and admired by all who knew him for his excellence as a physician, and humorous yet caring way with patients, learners and colleagues alike.

To describe the life of Ed Carter is to describe a life of considerable accomplishments. He finished medical school at the age of 18 in 1947. His 4 years of post-doctoral training in internal medicine included working with patients with polio including those with respiratory compromise. From 1954 to 1957 he served as a flight surgeon in the U.S. Air Force. After 2 years additional training in internal medicine and 3 in private practice, he joined the medical staff of The Institute of Rehabilitation and Research (TIRR), in Houston, Texas where he organized and directed the Spinal Cord Injury (SCI) Program.

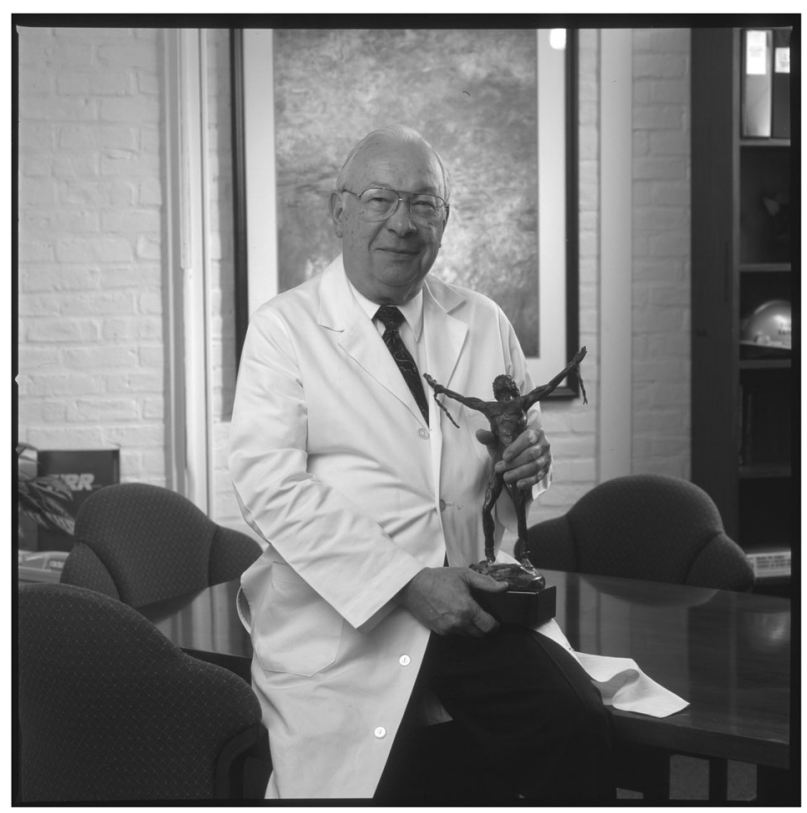

In 1973, that program was selected as a Model System for the nation funded in part by federal grants which still exists to this day. Ed became an acknowledged leader in the care and management of ventilator dependent tetraplegic patients both nationally and internationally. He was a founding member and first president of the American Spinal Injury Association (ASIA) from 1973 to 1977 and remained active for many years during which he served on the Executive Board and was awarded the Lifetime Achievement Award in 1991.

He was, along with John S. Young, M.D., one of the first American members of the International Spinal Cord Society (ISCoS). He was elected its second American President from 1988 to 1992 and received the Silver Medal, the society's highest award in 1991. He attended every Annual Scientific Meeting until 2009 and served on the Society Council and as Corresponding Secretary for the U.S. for many years.

Throughout his career, he remained committed to academics and rose to Professor in both the Departments of Internal Medicine and Physical Medicine and Rehabilitation at Baylor College of Medicine. He was well liked by all learners and colleagues who had the privilege of working with him. He was also recognized by the American Academy of Orthopedic Surgeons as an Associate Member and as an Honorary Member of the British Cervical Spine Society.

He met and married his wife, Ruth, in 1961 and had 2 children, Edward Jr. and Ruthie who blessed them with five grandchildren.

I will always fondly remember our discussions, especially those at the bar where the annual meetings were held, about science and SCI of course. I am sure he would approve if we lifted our glasses high and offered a toast to his long and remarkable life!

\footnotetext{
William Donovan

wdoctord@aol.com

1 https://www.nature.com/SpinalCord/
} 